RASĀYAN J. Chem.

Vol. 13 | No. 3 |1330-1334| July - September | 2020 ISSN: 0974-1496 | e-ISSN: 0976-0083 | CODEN: RJCABP

\title{
ISOLATION AND CHARACTERISATION OF FORCED DEGRADATION PRODUCTS OF A CALCIUM CHANNEL BLOCKER BY LC/MS TECHNIQUE
}

\author{
L. Sawaikar ${ }^{1,2, *}$ and P. Kapupara ${ }^{3}$ \\ ${ }^{1}$ PES's Rajaram and Tarabai Bandekar College of Pharmacy, Farmagudi-Ponda 403401, \\ Goa India \\ ${ }^{2}$ Research Scholar, R K University, Bhavnagar Highway, Kasturbadham, Rajkot 360020, \\ Gujarat India \\ ${ }^{3}$ School of Pharmacy, R K University, Bhavnagar Highway, Kasturbadham, Rajkot 360020, \\ Gujarat India \\ *E-mail: sawaikarleena@gmail.com
}

\begin{abstract}
The current study aims in carrying out forced degradation studies on Cilnidipine, a calcium channel blocker and identifying the degradants obtained when the drug is subjected to various stress conditions forcefully. The separation was carried out using Shimadzu, LC/MS model 8030 with lab solutions 5.72 B as software and a PDA detector. The wavelength selected was $240 \mathrm{~nm}$ with a flow rate $1.00 \mathrm{ml} / \mathrm{min}$. The column temperature was $40 \pm 0.3^{\circ} \mathrm{C}$ and the run time was $18 \mathrm{~min}$. The volume taken for injection was $5.0 \mu \mathrm{l}$. Phase A $(0.1 \%$ Formic acid in methanol: Acetonitrile in the ratio 80:20 v/v): phase $\mathrm{B},(10 \mathrm{mM}$ ammonium acetate) in gradient mode was used as a mobile phase. Cilnidipine when forced to degradation by various methods showed degradation showed four major degradants in basic conditions. From the mass spectra of the degradants, a probable structure was identified. Cilnidipine showed degradation only in basic conditions while remained stable under acidic, oxidative and photolytic conditions.
\end{abstract}

Keywords: Cilnidipine, LC/MS, Forced Degradation

(C) RASĀYAN. All rights reserved

\section{INTRODUCTION}

Hypertension or high blood pressure is a very common condition in primary care and is becoming a major health issue in the world. If not detected early and treated it may lead to complications. The symptoms of hypertension go undetected till major damage to organs is done and hence also called a silent killer. Cilnidipine a calcium channel blocker is used in the treatment of high blood pressure. It inhibits both Ltype and N-type voltage-dependent calcium channels. ${ }^{1-6}$ It has been classified as a fourth-generation calcium channel blocker based on its actions on sympathetic neurotransmitter release. Many simple and validated methods have been reported for the estimation of Cilnidipine in single and in bulk drug pharmaceutical dosage forms. ${ }^{7-13}$ This work was directed towards the forced degradation study of Cilnidipine in various mild to strong conditions.

\section{Materials and Methods}

\section{EXPERIMENTAL}

A free sample of Cilnidipine was obtained from ACME Generics Solan, Himachal Pradesh. HPLC/AR grade of chemicals and reagents were used for the work. LC/MS model 8030 of Shimadzu with lab solutions $5.72 \mathrm{~B}$ as software and a PDA detector was used for the analysis. The column used was X-

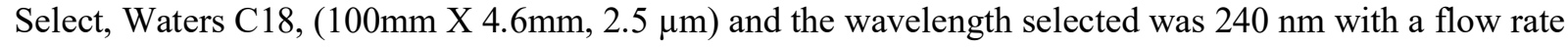
of $1.00 \mathrm{ml} / \mathrm{min}$. The column temperature was $40 \pm 0.3^{\circ} \mathrm{C}$ and the run time was 18 min with an injection volume of $5.0 \mu \mathrm{l}$ The mobile phase consisted of phase A, $(0.1 \%$ Formic acid in methanol: Acetonitrile in 
RASĀYAN J. Chem.

Vol. 13 | No. 3 |1330-1334| July - September | 2020

the ratio $80: 20 \mathrm{v} / \mathrm{v})$ : phase $\mathrm{B},(10 \mathrm{mM}$ ammonium acetate) in gradient mode. A quantity equivalent to 40 $\mathrm{mg}$ of Cilnidipine was dissolved in $10 \mathrm{ml}$ of methanol to give a concentration of $4 \mathrm{mg} / \mathrm{ml}$ of Cilnidipine. A solution containing $1.0 \mathrm{mg} / \mathrm{ml}$ of Cilnidipine was prepared by diluting the above solution with methanol. This was then stored in a refrigerator at $5 \pm 3^{\circ} \mathrm{C}$ and used within 7 days from the date of preparation.

\section{General Procedure For Degradation Forced Degradation Studies ${ }^{14-18}$ \\ Acid Hydrolysis}

To $1 \mathrm{ml}$ of the standard mixture, $1 \mathrm{ml}$ of $0.1 \mathrm{~N} \mathrm{HCl}$ was added in a flask for $1,6,12,24$ and 36 hours at room temperature. The solution was then kept to attain room temperature, neutralized with $0.1 \mathrm{~N}$ sodium hydroxide and diluted to reach the targeted concentration and injected in the system.

\section{Alkali Hydrolysis}

To $1 \mathrm{ml}$ of the standard mixture, $1 \mathrm{ml}$ of $1 \mathrm{~N}$ sodium hydroxide was added in a flask for and kept for 1,6 , 12,24 and 36 hours at room temperature. Once the solution attained the room temperature it was neutralized with $1 \mathrm{~N}$ hydrochloric acid. This was further diluted to reach a target concentration then injected into the system.

\section{Oxidative Stress}

To $1 \mathrm{ml}$ of the standard mixture in two flasks $1 \mathrm{ml}$ of $3 \%$ and $10 \%$ hydrogen peroxide at room temperature for 1,3 and 6 hours. The solution was cooled and diluted to reach a targeted concentration and then injected into the system.

\section{Photolytic Cleavage}

$1 \mathrm{ml}$ of the standard mixture was exposed to UV light $(254 \mathrm{~nm})$, in the UV chamber for 12, 24 and 48 hours. The mobile phase was used to dilute the above solution to get the required concentration. The solution was injected and the stability of the sample was accessed through the chromatograms.

\section{RESULTS AND DISCUSSION}

Forced degradation study was performed on a pure sample of Cilnidipine. In the present study, separation of Cilnidipine from its degradants was done by high-performance liquid chromatography. The major degradants were characterized by using their mass spectra. Cilnidipine was degraded in basic conditions and was stable in acidic oxidative and photolytic cleavage.

\section{Analysis of Basic Degradation Sample by LC/MS \\ Structural Identification of Degradation Products}

Liquid chromatography-mass spectroscopy was performed to identify the structure of Cilnidipine and its degradants The molecular ion and fragment ion peaks were identified using mass spectra of individual degradants.

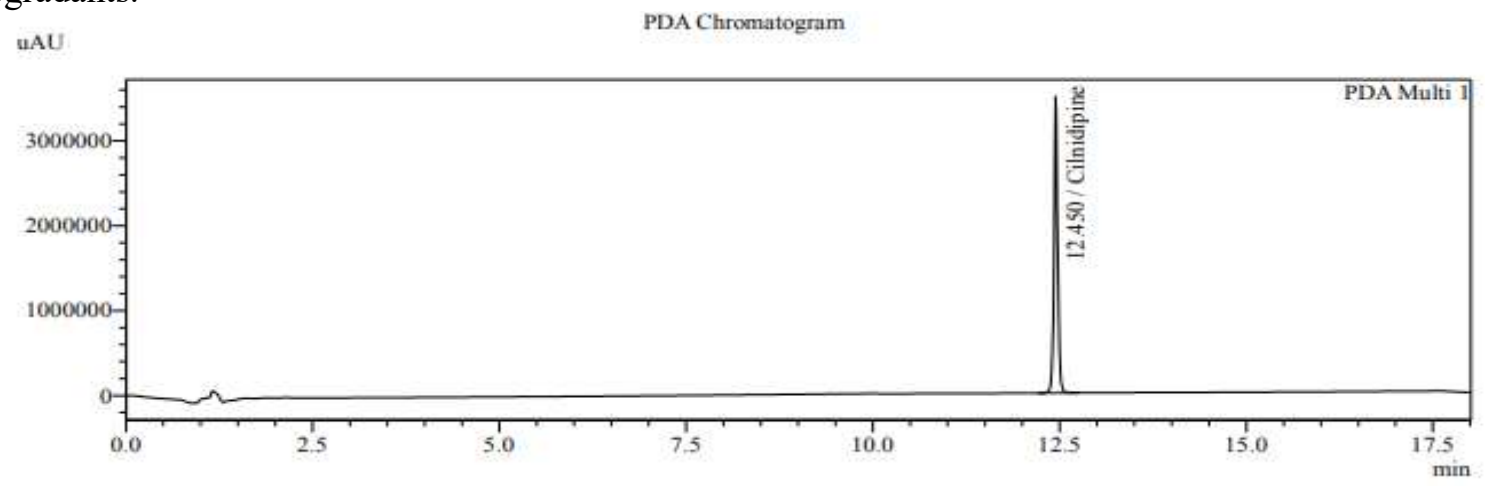

Fig.-1: HPLC Chromatogram of Cilnidipine (RT-12.04 min) 
RASĀYAN J. Chem.

Vol. 13 | No. 3 |1330-1334| July - September | 2020

IAU

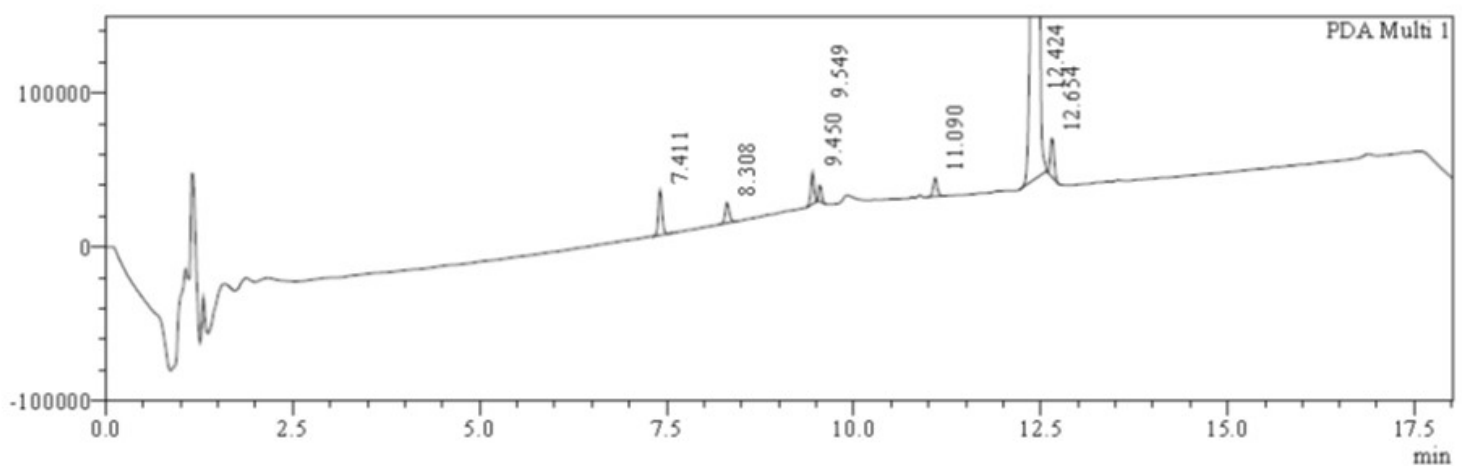

Fig.-2: HPLC Chromatogram of Base Degradation

Table 1: Forced Degradation of Cilnidipine

\begin{tabular}{c|c|c}
\hline S. No. & Pure Cilnidipine and Degradants & Retention Time in min \\
\hline 1 & Pure Cilnidipine & 12.424 \\
\hline 2 & Alkali Degradant 1 & 7.411 \\
\hline 2 & Alkali Degradant 2 & 8.308 \\
\hline 4 & Alkali Degradant 3 & 9.490 \\
\hline 5 & Alkali Degradant 4 & 9.690 \\
\hline
\end{tabular}

Table-2: Summary of the Structures of Degradants Obtained From Mass Spectra

\begin{tabular}{|c|c|c|c|}
\hline Condition & Structure & IUPAC Name & $\begin{array}{l}\text { Molecular } \\
\text { Weight }\end{array}$ \\
\hline Pure Cilnidipine & & $\begin{array}{l}\text { 3-cinnamyl-5(2- } \\
\text { methoxyethyl)-2,6- } \\
\text { dimethyl-4-(3- } \\
\text { nitrophenyl)-1,4- } \\
\text { dihydropyridine- } \\
\text { 3,5-dicarboxylate. }\end{array}$ & 492 \\
\hline Alkali Degradant 1 & & $\begin{array}{l}\text { (E)-1-(prop-1- } \\
\text { enyl)benzene }\end{array}$ & 117 \\
\hline Alkali Degradant 2 & & $\begin{array}{l}\text { 5-((2- } \\
\text { methoxyethoxy)car } \\
\text { bonyl)-2,6- } \\
\text { dimethyl-4-(3- } \\
\text { nitrophenyl)-1,4- } \\
\text { dihydropyridine-3- } \\
\text { carboxylic acid }\end{array}$ & 376 \\
\hline
\end{tabular}


RASĀYAN J. Chem.

Vol. 13 | No. 3 |1330-1334| July - September | 2020

\begin{tabular}{|c|c|c|}
\hline Alkali Degradant 3 & $\begin{array}{l}\text { (Z)-2,6-dimethyl-4- } \\
\text { (3-nitrophenyl)-5- } \\
\text { ((3- } \\
\text { phenylallyloxy)carb } \\
\text { onyl)-1,4- } \\
\text { dihydropyridine-3- } \\
\text { carboxylic acid }\end{array}$ & 434 \\
\hline Alkali Degradant 4 & $\begin{array}{l}\text { (Z)-3-phenylallyl } \\
\text { 2,6-dimethyl-4-(3- } \\
\text { nitrophenyl)-1,4- } \\
\text { dihydropyridine-3- } \\
\text { carboxylate }\end{array}$ & 390 \\
\hline
\end{tabular}

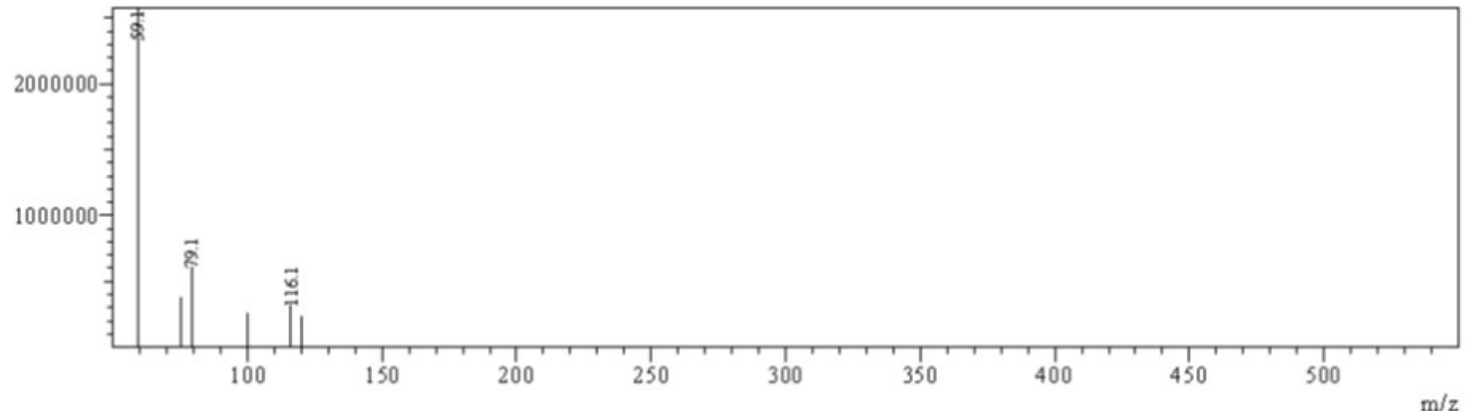

Fig.-3: LC/MS Spectrum of Degradant 1

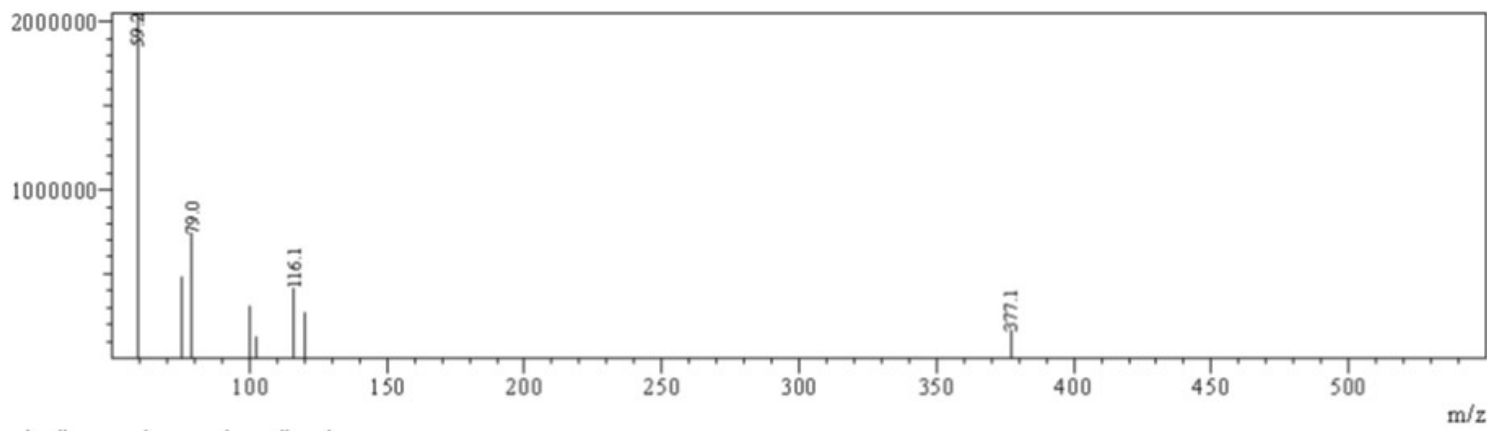

Fig.-4: LC/MS Spectrum of Degradant 2

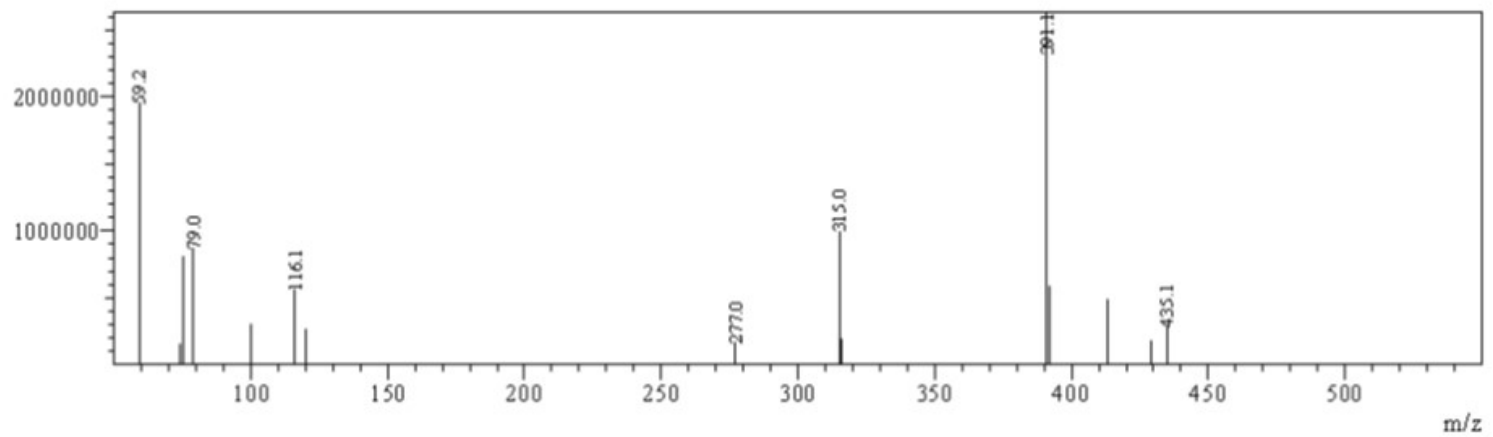

Fig.-5: LC/MS Spectrum of Degradant 3 
RASĀYAN J. Chem.

Vol. 13 | No. 3 |1330-1334| July - September | 2020

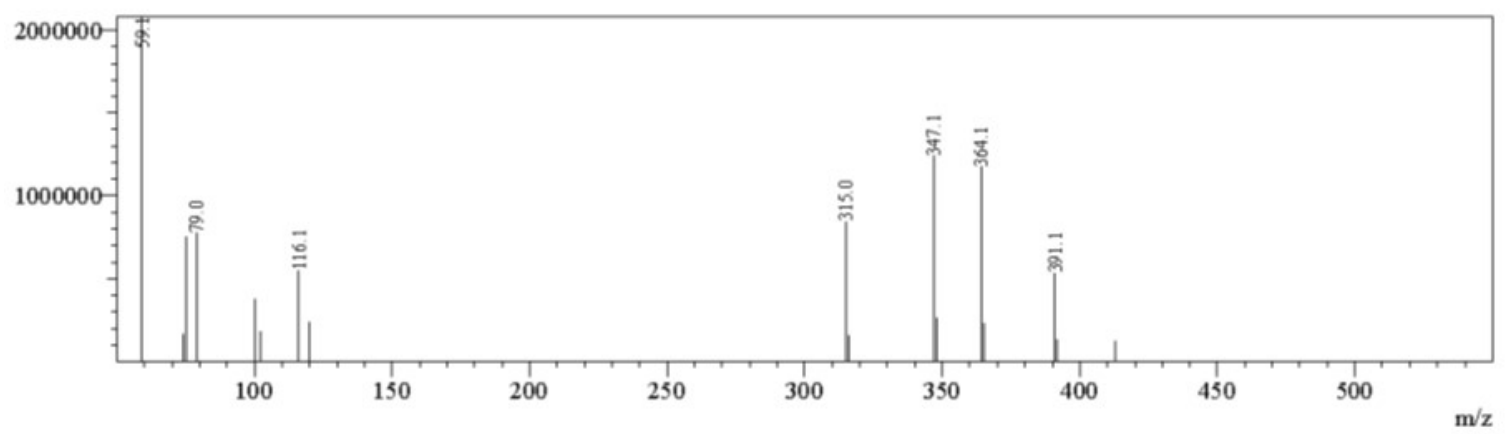

Fig.-6: LC/MS Spectrum of Degradant 4

\section{CONCLUSION}

Cilnidipine degraded in only one of the degradation conditions of the four. Degradation was seen in basic conditions. It remained stable in acidic conditions, oxidative conditions and photolytic cleavage. The generated prominent degradants were identified by LC/MS. The degradants obtained were (E)-1-(prop-1enyl)benzene, 5-((2-methoxyethoxy)carbonyl)-2,6-dimethyl-4-(3-nitrophenyl)-1,4-dihydropyridine-3carboxylic acid, (Z)-2,6-dimethyl-4-(3-nitrophenyl)-5-((3-phenylallyloxy)carbonyl)-1,4-dihydropyridine3-carboxylic acid and (Z)-3-phenylallyl 2,6-dimethyl-4-(3-nitrophenyl)-1,4-dihydropyridine-3carboxylate.

\section{ACKNOWLEDGMENT}

My sincere gratitude to my guide Dr. Pankaj Kapupara, for his guidance and support throughout the work. The authors are thankful to ACME Generics Solan, Himachal Pradesh for providing gift sample of the drug.

\section{REFERENCES}

1. M. M. Mukesh, Journal of The Association of Physicians of India, 64, 95(2016).

2. D. Arjit, K. Prakash, K. Abha, Cardiology Research, 7, 167(2016), DOI:10.14740/cr494w

3. K. Sawicka et al., Journal of Pre-Clinical and Clinical Research, 5, 43(2011).

4. K. D.Tripathi, Essentials of Medical Pharmacology,7th ed., Jaypee Brothers Medical Publishers Ltd., 2014.

5. K. S. Chamdra, G. Ramesh, Indian Heart Journal, 65, 691 (2013), DOI:10.1016/j.ihj.2013.11.001

6. https://pubchem.ncbi.nlm.nih.gov/compound/cilnidipine

7. A. Husain, Journal of Analytical \& Pharmaceutical Research, 3, 1(2016).

8. R.A. Kumar, A.Thomas, International Journal of Pharma and Bio Sciences, 9, 195(2018).

9. M. P. Ketulkumar, World Journal of Pharmacy and Pharmaceutical Science, 6, 1017(2017), DOI:10.20959/wjpps20175-9115

10. R. H Rupareliya, H. S. Joshi, International Journal of Pharmaceutical Quality Assurance, 7, 39(2016), DOI:10.1155/2013/46146

11. B. Tiwari, M. K. Shirsat, A. Kulkarni, Journal of Drug Delivery and Therapeutics, 10, 97(2020), DOI:10.22270/jddt.v10i1.3846

12. A. Kadam, S. Patil, International Journal of Pharmaceutical Sciences Review and Research, 30,177(2018).

13. K. Poonam, Research Journal of Pharmacy and Technology, 2, 621(2009).

14. P. K. Sinha, R. M. Jeswani, K. S. Topgi, M. C. Damle, Research Journal of Pharmacy and Technology, 3, 141(2010).

15. S. S. Quadri, L. V. Sonwane, B. N. Poul, S. N. Kamshett, Pharma Tutor, 2, 16(2014).

16. M. Blessy, R. D. Patel, P. N, Prajapati and Y. Agrawal, Journal of Pharmaceutical Analysis, 4, 159(2014), DOI:10.1016/j.jpha.2013.09.003

17. S. V.Sutar, V. C Yeligar, S. S. Patil, Research Journal of Pharmacy and Technology, 12, 885(2019), DOI:10.5958/0974-360X.2019.00152.5

[RJC-5855/2020] 